\title{
Absorção de nutrientes em cultivares de gérbera cultivada em vaso
}

\section{Fernanda Ludwig; Dirceu M Fernandes; Amaralina C Guerrero; Roberto L Villas Boas}

UNESP-FCA, Dep ${ }^{\text {to }}$ Recursos Naturais/Ciência do Solo, C. Postal 237, 18610-307, Botucatu-SP; ludwig.fernanda@yahoo.com.br; dmfernandes@fca.unesp.br; amaralina@fca.unesp.br; rlvboas@fca.unesp.br

\section{RESUMO}

A análise da absorção de nutrientes ao longo do ciclo da cultura é importante para o conhecimento das necessidades nutricionais nas épocas de maior demanda e programar a fertirrigação, sendo escassas as informações para gérbera. Assim, o objetivo foi quantificar a absorção das cultivares de gérbera de vaso Cherry e Red, conduzidas em substrato em um ciclo de cultivo no período de agosto a outubro de 2008. O experimento foi realizado em casa-de-vegetação com delineamento em blocos ao acaso, com parcela subdividida e 4 repetições. As parcelas foram compostas pelas cultivares e subparcelas pelas datas das coletas. Durante o desenvolvimento da cultura foram determinadas a fitomassa seca, o teor e acúmulo de nutrientes no tecido vegetal da parte aérea das plantas. Os macronutrientes foram absorvidos na seguinte ordem: $\mathrm{K}>\mathrm{N}>\mathrm{Ca}>\mathrm{Mg}>\mathrm{P}>\mathrm{S}(524,334,119$, 47, 42, $21 \mathrm{mg}$ planta $\left.^{-1}\right)$. Os micronutrientes foram absorvidos na seguinte ordem: $\mathrm{Fe}>\mathrm{Mn}>\mathrm{B}>\mathrm{Zn}>\mathrm{Cu}(7897,1505,801,384,63 \mu \mathrm{g}$ plant $\left.^{-1}\right)$. O período reprodutivo foi o de maior acúmulo de nutrientes, exceto para o Fe.

Palavras-chave: Gerbera jamesonii, cultivo sem solo, nutrição de plantas.

\begin{abstract}
Nutrient uptake in potted gerbera cultivars

The analysis of the uptake of nutrients is important for understanding the nutritional requirements of a cultivar during its development and identifies periods of increased demand, which allows scheduling fertigation. Nevertheless, the information is limited for gerbera. Thus, the present study was conducted to determine the uptake of potted gerbera cultivars Cherry and Red conducted in substrate in a crop cycle in the period August-October 2008. The experiment was carried out in a greenhouse in a randomized block split plot with four replications. The plots were composed by cultivars and subplots by dates of collection. During the development of the plants, the content and accumulation of macro and micronutrients was assessed in plant tissue of the shoots. The macronutrients were accumulated in the following order: $\mathrm{K}>\mathrm{N}>\mathrm{Ca}>\mathrm{Mg}>\mathrm{P}>\mathrm{S}(524,334$, $119,47,42,21 \mathrm{mg}$ plant $\left.^{-1}\right)$. The micronutrients were accumulated in the following order: $\mathrm{Fe}>\mathrm{Mn}>\mathrm{B}>\mathrm{Zn}>\mathrm{Cu}(7897,1505,801,384,63$ $\mu \mathrm{g}$ plant $\left.^{-1}\right)$. The reproductive was the period of greatest uptake of nutrients, except for Fe.
\end{abstract}

Keywords: Gerbera jamesonii, soilless culture, plant nutrition.

(Recebido para publicação em 9 de novembro de 2012; aceito em 11 de outubro de 2013) (Received on November 9, 2012; accepted on October 11, 2013)

A gérbera (Gerbera jamesonii), pertencente à família Asteraceae e é originária do sul da África e Ásia (Radice \& Marconi, 1998), é uma planta popular como flor de corte, flor envasada e na forração de jardins (Jeong et al., 2009). A qualidade na sua produção é influenciada pelos substratos utilizados, sendo encontrados resultados positivos quando esses promovem aeração adequada na zona radicular (Mascarini, 1998) e quando os valores de pH estão entre 5,5 e 6,5 (Rogers \&Tjia, 1990).

O cultivo em recipiente com substrato limita o espaço disponível ao sistema radicular, o que implica no fornecimento de nutrientes, que deve ser preciso. Com a suplementação insuficiente desses, as culturas rapidamente apresentam sintomas de deficiência, enquanto a suplementação excessiva pode levar a um indesejável aumento da salinidade e pressão osmótica (Sonneveld, 2000).

A fim de evitar os problemas relacionados à salinidade ou à deficiência de nutrientes, o conhecimento da marcha de absorção é importante para determinar as épocas em que os mesmos são exigidos em maior quantidade e quando a adubação deve fornecê-los, além de possibilitar a correção de eventuais deficiências e avaliação do estado nutricional (Malavolta et al., 1997). Trabalhos conduzidos com gérbera de vaso têm demonstrado que o período reprodutivo é o de maior exigência nutricional da cultura (Guerrero et al., 2012; Ludwig et al., 2008), porém não há detalhamento quanto a períodos mais precisos ao longo do ciclo.

As plantas de gérbera de vaso são moderadamente exigentes em nutrição, de modo que níveis sub-ótimos de fertilidade acarretam em amarelecimento das folhas devido à deficiência de nutrientes; fertilidade excessiva pode levar ao rápido crescimento vegetativo e atraso no florescimento. $\mathrm{O}$ equilíbrio entre as necessidades da planta e o monitoramento periódico pode ajudar a assegurar as necessidades nutricionais (Jeong et al., 2009).

A análise da marcha de absorção de nutrientes é importante para o conhecimento das necessidades nutricionais da cultura ao longo do seu desenvolvimento. Com base nessas informações, é possível identificar os períodos de maior demanda de nutrientes e programar a fertirrigação. Desse modo, objetivou-se determinar a marcha de absorção de nutrientes das cultivares de gérbera de vaso 'Cherry' e 'Red', conduzidas em 
substrato ao longo de um ciclo de cultivo no período de agosto a outubro de 2008.

\section{MATERIAL E MÉTODOS}

O experimento foi conduzido em casa-de-vegetação no município de Botucatu-SP (22 $51^{\prime}$ 'S, 48²6’W), nos meses de agosto a outubro de 2008. O ambiente protegido apresentou cobertura em arco com plástico transparente de $150 \mu \mathrm{m}$ de espessura, com laterais de tela branca, cortinas de plástico transparente e pavimentado com concreto, em uma área total de $168 \mathrm{~m}^{2}$ (7x24 m) e 2,6 $\mathrm{m}$ de pé direito. A temperatura média no interior do ambiente foi de $23^{\circ} \mathrm{C}$ e a umidade relativa média do ar de $63 \%$, durante o período experimental.

As mudas, com quatro folhas definitivas, foram transplantadas em vasos com capacidade para $1 \mathrm{~L}(11,5 \mathrm{~cm}$ de altura, $13 \mathrm{~cm}$ de base superior e $9 \mathrm{~cm}$ de base inferior), preenchidos com o substrato, de acordo com a densidade úmida em junho de 2008. Estas foram aclimatadas durante 30 dias, dispostas sobre bancada de madeira $(1,2 \mathrm{~m}$ de largura, $12,0 \mathrm{~m}$ de comprimento e 0,8 m de altura), sob malhas termorefletoras (Aluminet $^{\circledR}$ ) que mantinham a intensidade luminosa próxima a 25.000 Lux, aferido com luxímetro digital da marca Instrutherm, modelo LD 200. Após a aclimatação, os vasos foram espaçados de 25 em $25 \mathrm{~cm}$ e distribuídos em duas bancadas, permanecendo na intensidade luminosa máxima de 50.000 Lux. A avaliação experimental iniciou-se após a aclimatação e os resultados são apresentados em dias após a aclimatação (DAA).

O delineamento experimental adotado foi de blocos ao acaso, com parcela subdividida e 4 repetições, sendo as parcelas compostas pelas cultivares e subparcelas pelas datas das coletas. As cultivares utilizadas foram Cherry e Red, pertencentes à série 'Dark eyes' da empresa Sakata Seed Sudamerica. As coletas foram realizadas aos 1, 15, 29, 43 e 50 dias após a aclimatação (DAA), as três primeiras referentes ao período vegetativo e as duas últimas ao período reprodutivo. $\mathrm{O}$ período entre as duas últimas avaliações foi inferior, pois as plantas atingiram o ponto de comercialização, adotado como requisito para o encerramento do experimento.

O substrato utilizado foi constituído de $30 \%$ casca de pinus, $30 \%$ da mistura ( $40 \%$ casca de pinus $+30 \%$ vermiculita $+30 \%$ casca de arroz carbonizada), 20\% fibra de coco granulada e $20 \%$ fibra de coco mista (textura intermediária entre o fibroso e o granulado). O mesmo apresentou condutividade elétrica de $0,28 \mathrm{dS} \mathrm{m}^{-1}$ e $\mathrm{pH}$ de 5,74, analisados pelo método de diluição do 1:5 (Brasil, 2007), os seguintes nutrientes, em mg $\mathrm{L}^{-1}: 1,75 \mathrm{~N}^{-\mathrm{NH}_{4}^{+}}, 12,72 \mathrm{~N}^{-\mathrm{NO}_{3}}-, 56,70$ $\mathrm{K}, 22,83 \mathrm{Ca}, 24,45 \mathrm{Mg}, 0,03 \mathrm{Cu}, 1,76$ $\mathrm{Fe}, 0,38 \mathrm{Mn}, 0,06 \mathrm{Zn}$, analisados pelo método de diluição do 1:1,5 (Sonneveld \& Elderen, 1994), densidade úmida e seca (Brasil, 2007) de $590 \mathrm{~kg} \mathrm{~m}^{-3}$ e 298 $\mathrm{kg} \mathrm{m}^{-3}$, respectivamente e porosidade total, sólidos, espaço de aeração, água disponível e água remanescente (De Boodt \& Verdonck, 1972) de 89,18\%, $10,82 \%, 17,15 \%, 35,80 \%$ e $36,23 \%$, respectivamente.

O manejo da fertirrigação baseou-se na pesagem diária dos vasos, os quais foram mantidos na faixa de 25 a $50 \%$ da água disponível no substrato. A solução nutritiva aplicada apresentou a seguinte composição em mg L-1: 121 N-NO - 12 $\mathrm{N}-\mathrm{NH}_{4}^{+}, 92 \mathrm{~K}, 24 \mathrm{P}, 175 \mathrm{Ca}, 27 \mathrm{Mg}$ e 39 $\mathrm{S}, 0,19 \mathrm{~B}, 0,08 \mathrm{Cu}, 2,74 \mathrm{Fe}, 0,19 \mathrm{Mn}$, $0,04 \mathrm{Mo}$ e $0,08 \mathrm{Zn}$ na fase vegetativa e

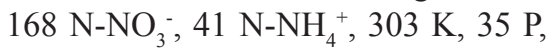
$105 \mathrm{Ca}, 45 \mathrm{Mg}$ e $55 \mathrm{~S}, 0,19 \mathrm{~B}, 0,08 \mathrm{Cu}$, 2,74 Fe, 0,19 Mn, 0,04 Mo e 0,08 Zn na fase reprodutiva.

Nos períodos de coleta, a parte aérea das plantas foi cortada rente ao substrato, lavada e posta para secar em estufa de ventilação forçada a $65^{\circ} \mathrm{C}$ até fitomassa constante, sendo então pesada em balança digital, separada em folhas e inflorescências. Em seguida as amostras foram moídas em moinho tipo 'Willey' e determinado o teor de nitrogênio $(\mathrm{N})$, fósforo $(\mathrm{P})$, potássio $(\mathrm{K})$, cálcio $(\mathrm{Ca})$, magnésio $(\mathrm{Mg})$, enxofre $(\mathrm{S})$, boro $(\mathrm{B})$, cobre $(\mathrm{Cu})$, ferro $(\mathrm{Fe})$, manganês $(\mathrm{Mn})$ e zinco ( $\mathrm{Zn}$ ) de acordo com metodologia proposta por Malavolta et al. (1997). O acúmulo dos nutrientes foi calculado pelo produto da fitomassa seca pelas respectivas concentrações.

Os resultados obtidos foram sub- metidos à análise de variância pelo teste F. As médias das cultivares foram comparadas pelo teste Tukey a 5\% de probabilidade e os efeitos das épocas foram submetidos à análise de regressão, testando os modelos linear e quadrático. Procedeu-se o desdobramento da interação entre cultivares e épocas, quando significativo. Utilizou-se o programa estatístico Sisvar (Ferreira, 2000).

\section{RESULTADOS E DISCUSSÃO}

As cultivares de gérbera apresentaram diferença quanto ao acúmulo de fitomassa seca aos 43 e 50 DAA, sendo maior para a cultivar Cherry (Figura 1A). Diferença entre cultivares de gérbera de vaso para a fitomassa seca foi registrada em trabalhos desenvolvidos por Ludwig et al. (2010) e Mota (2007), afirmando ser uma característica inerente à cultivar.

A fitomassa seca da parte aérea total apresentou maiores acréscimos dos 29 aos 43 DAA (Figura 1A), coincidindo com o período reprodutivo e a emissão das inflorescências, representado por 2,5 $\mathrm{g}$ de incremento para as folhas e 3,9 $\mathrm{g}$ para as inflorescências (Figura 1B). Nas folhas, o maior acúmulo de fitomassa foi de 2,7 g e ocorreu dos 1 aos 15 DAA e nas inflorescências foi de com 3,9 $\mathrm{g}$ dos 29 aos 43 DAA (Figura 1B). De acordo com Larcher (1986) as plantas de ciclo curto apresentam a tendência de usar uma maior proporção de fotoassimilados para a formação de folhas no início do crescimento, as quais participam da produção e aumentam a absorção da planta. Na fase de floração, o sistema de distribuição passa a favorecer os órgãos reprodutores, em detrimento de outras partes da planta, as quais são supridas com pouco mais do que o necessário para manutenção. A gérbera é uma planta originalmente perene, cultivada como anual, com ciclo relativamente curto.

A cultivar Cherry acumulou mais $\mathrm{N}$ que Red, significativamente aos 43 e 50 DAA (Figura 2A). Diferença entre cultivares de gérbera de vaso para o acúmulo de $\mathrm{N}$ foi registrada também por Ludwig et al. (2008) e Mota (2007). A distribuição quanto à absorção de $\mathrm{N}$, para as duas cultivares, foi de $9 \%$ du- 


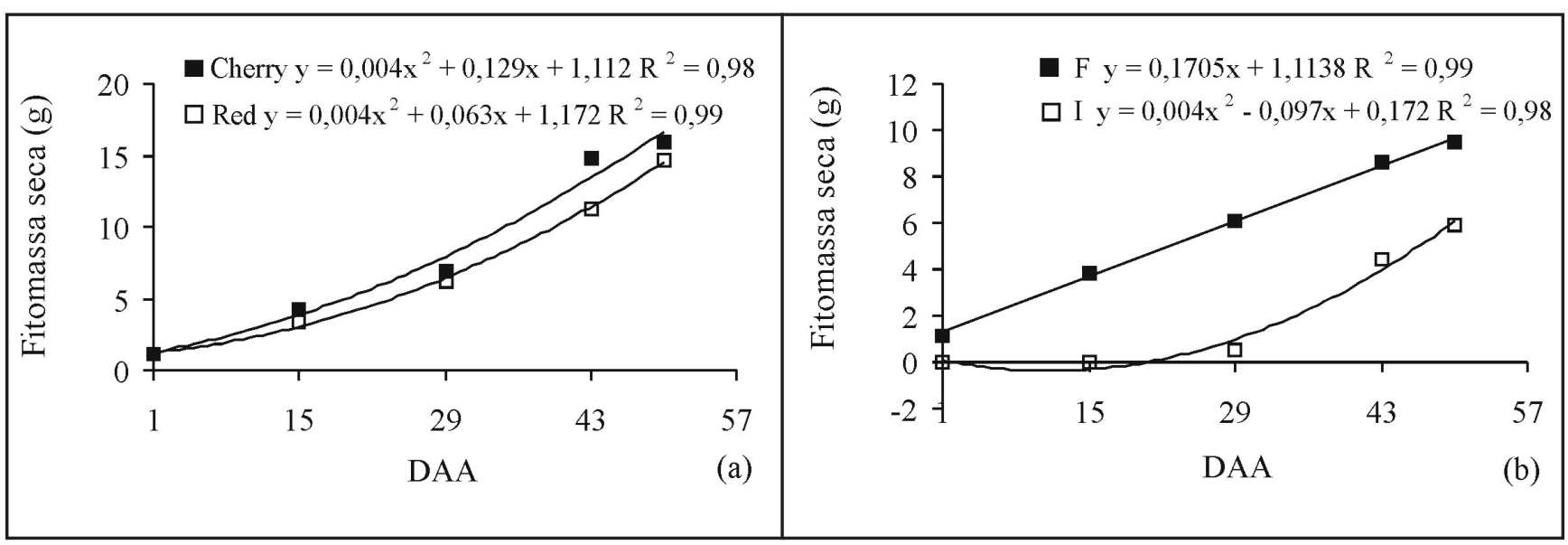

Figura 1. Acúmulo de fitomassa seca total em plantas de gérbera cultivares Red e Cherry (A) e distribuição de fitomassa em folhas (F) e inflorescências (I) em plantas de gérbera (B) ao longo do ciclo produtivo (total dry biomass accumulation in Cherry and Red cultivars of gerbera (A) and distribution of biomass in leaves (F) and inflorescences (I) in gerbera plants (B) throughout the production cycle). Botucatu, UNESP. 2008.

rante o período de aclimatação, $24 \%$ até os 15 DAA, 44\% até os 29 DAA, $80 \%$ até os 43 DAA e 100\% aos 50 DAA, quando a planta encontrava-se em ponto de comercialização. O maior acúmulo de $\mathrm{N}$ foi registrado dos 29 aos 43 DAA, de $15 \mathrm{~g} \mathrm{dia}^{-1}$ para Cherry e 9,6 $\mathrm{g} \mathrm{dia}^{-1}$ para Red, com $36 \%$ do total, coincidindo com o maior acúmulo de fitomassa seca total da parte aérea (Figura 1).

$\mathrm{O}$ crescente acúmulo de $\mathrm{N}$ durante todo o período relaciona-se com o constante desenvolvimento da fitomassa seca das folhas (Figura 1B), já que esse nutriente está relacionado principalmente com o crescimento vegetativo (Barbosa et al., 2009).

$\mathrm{O}$ acúmulo de $\mathrm{P}$ foi semelhante estatisticamente para as duas cultivares obedecendo a uma equação quadrática (Figura 2B). Assemelhando-se ao N, as plantas apresentaram a absorção de $\mathrm{P}$ de $12 \%$ durante a aclimatação, $24 \%$ até os 15 DAA, $45 \%$ até os 29 DAA, $81 \%$ até os 43 DAA e $100 \%$ aos 50 DAA. Assim, o maior acúmulo foi registrado dos 29 aos 43 DAA, de 1,8 $\mathrm{g} \mathrm{dia}^{-1}$, com $36 \%$ do total, sendo $55 \%$ no período reprodutivo. De maneira mais acentuada ao verificado no presente trabalho, onde a quantidade de $\mathrm{P}$ acumulada duplicou ao longo do período reprodutivo, Ludwig et al. (2008) registraram absorção três vezes superior nos últimos 21 dias de produção, coincidindo com o período reprodutivo. Esses resultados reafirmam a grande demanda desse nutriente no terço final do ciclo da gérbera.

A crescente demanda de $\mathrm{P}$ ao longo do ciclo de plantas ornamentais foi evidenciada também por Barbosa et al. (2009), os quais afirmaram que a deficiência de $\mathrm{P}$ reduz o número e o tamanho das flores. Dessa forma, em plantas ornamentais na fase de florescimento as necessidades desse nutriente são maiores e sua deficiência reflete na redução da qualidade da inflorescência.

Não foi constatada diferença significativa entre as cultivares de gérbera para o acúmulo de $\mathrm{K}$ (Figura 2C). A absorção desse nutriente para as plantas de gérbera foi de $10 \%$ durante a aclimatação, 23\% até os 15 DAA, 44\% até os 29 DAA, $76 \%$ até os 43 DAA, e $100 \%$ aos 50 DAA. Portanto, o maior acúmulo deu-se dos 29 aos 43 DAA, com $15,7 \mathrm{~g} \mathrm{dia}^{-1}$, representando $32 \%$ do total, sendo $56 \%$ do acúmulo registrado no período reprodutivo. A cultura da gérbera apresenta alta demanda por $\mathrm{K}$, principalmente na fase de florescimento (Damasceno et al., 2011). Uma das razões para a alta exigência de $\mathrm{K}$, usualmente o cátion mais abundante na planta, possivelmente seja a necessidade de concentrações elevadas no citoplasma para garantir a atividade enzimática ótima (Malavolta, 2006).

Requerimentos diferenciados de $\mathrm{Ca}$ foram observados para as cultivares, sendo superior para Cherry aos 43 e 50 DAA (Figura 2D). Diferença entre cultivares para a absorção desse nutriente também foi verificada por Ludwig et al. (2008) e Mota (2007).

$\mathrm{O}$ acúmulo do Ca para as plantas de gérbera foi de $9 \%$ durante a aclimatação, $21 \%$ até os 15 DAA, $45 \%$ até os 29 DAA, $75 \%$ até os 43 DAA e $100 \%$ aos 50 DAA. O maior acúmulo deu-se dos 29 aos 43 DAA, com 5,1 g planta $^{-1}$ para Cherry e 3,1 g planta ${ }^{-1}$ para Red, representando $30 \%$ do total, sendo $55 \%$ do acúmulo registrado no período reprodutivo. Semelhante ao presente experimento, Guerrero et al. (2012) verificaram que o acúmulo de Ca nas folhas foi superior no estádio reprodutivo.

Ao avaliar níveis de condutividade elétrica da solução nutritiva em plantas de gérbera, Mota (2007) afirmou que o Ca é absorvido durante todo o período de produção, não devendo ser fornecido para a planta apenas na fase vegetativa, como acontece na rotina dos produtores de flores. Essa afirmação encontra respaldo nos resultados obtidos.

Maiores acúmulos de $\mathrm{Mg}$ foram observados para a cultivar Cherry em relação a Red aos 43 e 50 DAA (Figura $2 \mathrm{E})$. Diferenças entre cultivares quanto ao acúmulo desse nutriente também foram obtidos por Ludwig et al. (2008) e Mota (2007).

As plantas de gérbera apresentaram a absorção de $\mathrm{Mg}$ de $10 \%$ durante a aclimatação, 24\% até os 15 DAA, 48\% até os 29 DAA, $77 \%$ até os 43 DAA e $100 \%$ aos 50 DAA. Registrou-se o maior acúmulo dos 29 aos 43 DAA, representando 
$29 \%$ do total, sendo $52 \%$ do acúmulo no período reprodutivo. Guerrero et al. (2012) também verificaram aumento no acúmulo de $\mathrm{Mg}$ no período reprodutivo.

Diferença entre cultivares de gérbera foi registrada para a absorção de $\mathrm{S}$, sendo superior para a cultivar Cherry (Figura 2F) concordando com resultados encontrados por Ludwig et al. (2008). A porcentagem de acúmulo do $\mathrm{S}$ foi de $9 \%$ durante a aclimatação, $25 \%$ até os 15 DAA, 44\% até os 29 DAA, 76\% até os 43 DAA e $100 \%$ aos 50 DAA. O maior acúmulo deu-se dos 29 aos 43 DAA, com 1,9 g planta ${ }^{-1}$ para Cherry e 1,3 g planta $^{-1}$ para Red, representando $32 \%$ do total, sendo $56 \%$ do acúmulo registrado no período reprodutivo. $\mathrm{O}$ acúmulo deste nutriente praticamente dobrou ao final do ciclo de cultivo de gérbera, em trabalho conduzido por Guerrero et al. (2012).

As cultivares de gérbera Red e Cherry não apresentaram variação significativa quanto ao acúmulo dos micronutrientes no tecido vegetal da parte aérea total (Figura 3). Porém, algumas cultivares podem apresentar demanda diferenciada, em função da característica genética, como a verificada por Ludwig (2007), com menor demanda de micronutrientes para Orange, em relação à Cherry, Golden Yellow, Salmon Rose.

$\mathrm{O}$ acúmulo de $\mathrm{B}$ foi de $15 \%$ durante a aclimatação, 25\% até os 15 DAA, $41 \%$ até os 29 DAA, $89 \%$ até os 43 DAA e $100 \%$ aos 50 DAA (Figura 3A). O maior acúmulo deu-se dos 29 aos 43 DAA, com taxa diária de absorção de

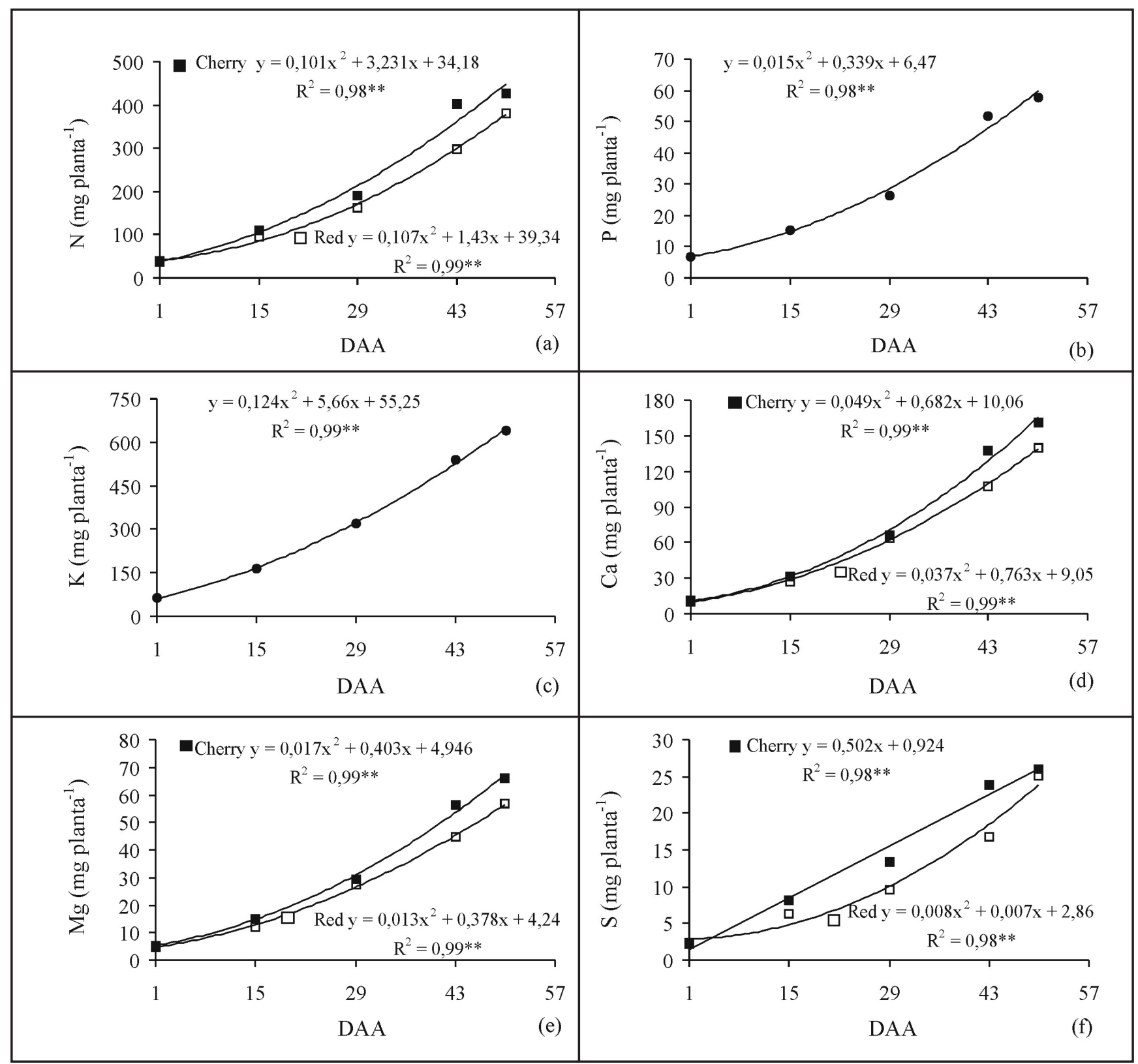

Figura 2. Acúmulo de macronutrientes em cultivares de gérbera, Cherry e Red, ao longo do período de crescimento (macronutrient accumulation in gerbera cultivars, Cherry and Red, throughout the production cycle). Botucatu, UNESP. 2008. 
$27 \mu \mathrm{g}$ planta $^{-1}$ representando $48 \%$ do total, sendo $59 \%$ registrado no período reprodutivo. Acúmulo três vezes superior no período reprodutivo, para o $\mathrm{B}$, foi observado por Ludwig (2007).

$\mathrm{O}$ acúmulo de $\mathrm{Cu}$ foi de $18 \%$ durante a aclimatação, 29\% até os 15 DAA, $41 \%$ até os 29 DAA, $73 \%$ até os 43 DAA e $100 \%$ aos 50 DAA (Figura 3B). O maior acúmulo deu-se dos 29 aos 43 DAA, com taxa diária de absorção de 1,6 $\mu \mathrm{g}$ planta $^{-1}$, representando $32 \%$ do total, sendo $59 \%$ do acúmulo registrado no período reprodutivo.

As plantas de gérbera apresentaram a absorção de Fe de 15\% durante a aclimatação, 34\% até os 15 DAA, $73 \%$ até os 29 DAA, $87 \%$ até os 43 DAA e $100 \%$ aos 50 DAA (Figura 3C). Registrou-se o maior acúmulo dos 15 aos 29 DAA, com taxa diária de acúmulo de $197 \mu \mathrm{g}$ planta $^{-1}$, representando $38 \%$ do total, sendo $81 \%$ no período vegetativo. Esse nutriente apresentou comportamento diferenciado em relação aos demais, pois seu maior acúmulo deu-se no período vegetativo. Resultado discordante foi obtido por Ludwig (2007), com acúmulo 3,7 vezes superior no período reprodutivo. A elevada retenção de água no substrato pode ter contribuído para a redução do oxigênio disponível para as plantas, e disponibilizado maior quantidade desse nutriente, apesar de não ser verificada toxidez visual. Segundo Malavolta (2006), em condições anaeróbicas, pode ocorrer toxidez de ferro pelas culturas, devido à redução do $\mathrm{Fe}^{+3}$ a $\mathrm{Fe}^{+2}$.

Em relação ao $\mathrm{Mn}$, as plantas absor-
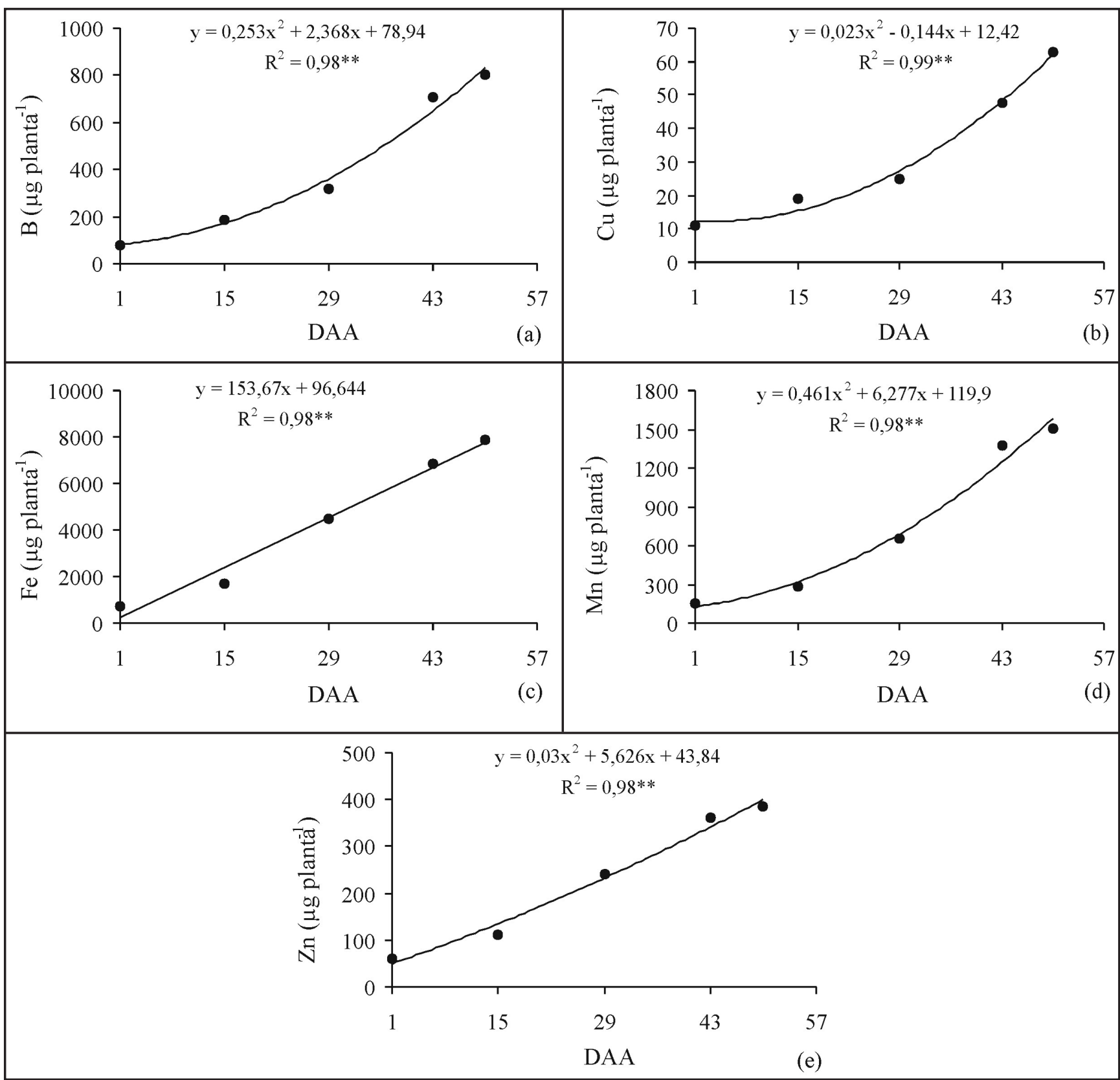

Figura 3. Acúmulo de micronutrientes em cultivares de gérbera, Cherry e Red, ao longo do período de crescimento (micronutrient accumulation in gerbera cultivars, Cherry and Red, throughout the production cycle). Botucatu, UNESP. 2008. 
veram $17 \%$ durante a aclimatação, $31 \%$ até os 15 DAA, $60 \%$ até os 29 DAA, $92 \%$ até os 43 DAA e $100 \%$ aos 50 DAA (Figura 3D). O maior acúmulo deu-se dos 29 aos 43 DAA, com taxa diária de $50 \mu \mathrm{g}$ planta $^{-1}$, representando $32 \%$ do total, sendo $66 \%$ do acúmulo registrado no período reprodutivo.

A absorção de $\mathrm{Zn}$ foi de $18 \%$ durante a aclimatação, 33\% até os 15 DAA, $58 \%$ até os 29 DAA, $87 \%$ até os 43 DAA e 100\% aos 50 DAA (Figura 3E). O maior acúmulo deu-se dos 29 aos 43 DAA, com taxa diária de acúmulo de $9 \mu \mathrm{g}$ planta $^{-1}$, representando $29 \%$ do total, sendo $63 \%$ registrado no período reprodutivo.

O maior incremento no acúmulo dos nutrientes deu-se dos 29 aos 43 DAA, época em que se inicia a diferenciação floral, aumentando consequentemente a demanda de nutrientes. Esse resultado é concordante com os obtidos por Mota (2007), o qual sugere que os nutrientes são absorvidos mais intensamente no período dos 28 aos 42 dias após a aclimatação. Ludwig et al. (2008) e Guerrero et al. (2012) registraram maior acúmulo durante o período reprodutivo, indicando a importância da adubação nesta fase da cultura.

Esse resultado corrobora com a afirmação de Haag et al. (1981) os quais indicaram que a absorção de nutrientes varia com a fase de desenvolvimento da cultura, intensificando-se no florescimento. De acordo com Taiz \& Zeiger (2009), nesse período ocorre o estabelecimento de uma força mobilizadora de nutrientes e assimilados, devido ao aumento da atividade metabólica, associada à atividade hormonal e à divisão e crescimento celular.

A quantidade de nutrientes acumulada na parte aérea de plantas de gérbera, cultivares Cherry e Red, é reduzida até os 15 DAA, aumentando consideravelmente após os 29 DAA, sugerindo que a fertirrigação deva ser realizada de maneira mais concentrada no período reprodutivo. Em razão do grande aumento no acúmulo de fitomassa, o período reprodutivo foi o de maior acúmulo de nutrientes.

Os macronutrientes foram absorvidos na seguinte ordem: $\mathrm{K}>\mathrm{N}>\mathrm{Ca}>\mathrm{Mg}>\mathrm{P}>\mathrm{S}$ (524, 334, 119, 47, 42, $\left.21 \mathrm{mg} \mathrm{planta}^{-1}\right)$. Os micronutrientes foram absorvidos na seguinte ordem: $\mathrm{Fe}>\mathrm{Mn}>\mathrm{B}>\mathrm{Zn}>\mathrm{Cu}$ (7897, 1505, 801, 384, $63 \mu \mathrm{g}$ planta $\left.^{-1}\right)$. $\mathrm{O}$ período reprodutivo foi o de maior acúmulo de nutrientes, exceto para o Fe.

\section{REFERÊNCIAS}

BARBOSA JG; BARBOSA MS; MUNIZ MA; CROSSI JAS. 2009. Nutrição mineral e adubação de plantas ornamentais. Informe Agropecuário 30: 16-21.

BRASIL. Instrução Normativa n. 17, de 21 de maio de 2007. Aprova os métodos analíticos oficiais para análise de substratos e condicionadores de solos. Diário Oficial da União, Brasília, 24 maio. 2007. Seção 1, p.8.

DAMASCENO MOL; ANDRADE JÚNIOR AS; GHEYI HR; DIAS NS; SILVA CO. 2011. Composição nutricional foliar da gérbera irrigada com efluente doméstico tratado. Revista Caatinga 24: 21-128.

De BOODT M; VERDONCK O. 1972. The physical properties of the substrates in horticulture. Acta Horticulturae 26: 37-44.

FERREIRA DF. Análises estatísticas por meio do Sisvar para Windows versão 4.0. 2000. In: REUNIÃO ANUAL DA REGIÃO BRASILEIRA DA SOCIEDADE INTERNACIONAL DE BIOMETRIA, 45. Anais...UFSCar, São Carlos. p. 255-258.

GUERRERO AC; FERNANDES DM; LUDWIG F. 2012. Acúmulo de nutrientes em gérbera de vaso em função de fontes e doses de potássio. Horticultura Brasileira 30: 201-208.

HAAG PH; OLIVEIRA GD; BARBOSA V; SILVA NETO JM. 1981. Marcha de absorção de nutrientes pelo tomateiro (Licopersicum esculentum Mill) destinado ao processamento industrial. In: HAAG HP; MINAMI K. (eds).
Nutrição mineral de hortaliças. Campinas: Fundação Cargill. p. 447-474.

JEONG KY; WHIPKER B; MCCALLI; GUNTER C; FRANTZ J. 2009. Characterization of nutrient disorders of gerbera hybrid 'Festival Light Eye Pink'. Acta Horticulturae 843: 177-182.

LARCHER W. 1986. Ecofisiologia vegetal. São Paulo: EPU, 319p.

LUDWIG F. 2007. Cultivares de gérbera (Gerbera jamesonii L.), em vaso, sob dois níveis de fertirrigação. Botucatu: UNESPFCA. 79p. (Tese mestrado).

LUDWIG F; FERNANDES DM; MOTA PRD; VILLAS BOAS RL. 2008. Macronutrientes em cultivares de gérbera sob dois níveis de fertirrigação. Horticultura Brasileira 26: 68-73.

LUDWIG F; FERNANDES DM; MOTA PRD; VILLAS BOAS RL. 2010. Crescimento e produção de gérbera fertirrigada com solução nutritiva. Horticultura Brasileira 28: 424-429.

MALAVOLTA E. 2006. Manual de nutrição mineral de plantas. São Paulo. Ceres, 638 p.

MALAVOLTA E; VITTI GC; OLIVEIRA SA. 1997. Avaliação do estado nutricional das plantas: princípios e aplicações. Piracicaba: Potafos, 319p.

MASCARINI L. 1998. Gerbera cultivation in growing media. Horticultura Internacional 6: 86-88.

MOTA PRD. 2007. Aplicação via fertirrigação de soluções com diferentes condutividades elétricas para produção de gérbera (Gerbera jamesonii L.) sob ambiente protegido. Botucatu: UNESP-FCA. 149p. (Tese doutorado).

RADICE S; MARCONI PL. 1998. Clonación in vitro de diversas cultivares de Gerbera jamesonii a partir de capítulos florales. Revista de la Facultad de Agronomía 103: 111-118.

ROGERS MN; TJIA BO. 1990. Gerbera production for cut flowers and pot plants. Portland: Timber Press, 116p.

SONNEVELD C. 2000. Effects of salinity on substrate grown vegetables and ornamentals in greenhouse horticulture. Wageningen: Wageningen Universitiet. 150p. (Tese doutorado).

SONNEVELD C; ELDEREN CW. 1994. Chemical analysis of peaty growing media by means of water extraction. Communication on Soil Science and Plant Analysis 25: 31993208 .

TAIZ L; ZEIGER E. 2009. Fisiologia Vegetal. Sunderland: Sinauer Associates, 819p. 